\title{
Validation of Curriculum Design Information System Model
}

\author{
Thong Chee Ling, Yusmadi Yah Jusoh, Rusli Abdullah, Nor Hayati Alwi \\ UCSI University, Kuala Lumpur, Sarawak, Terengganu, Malaysia
}

\begin{tabular}{l} 
Article Info \\
\hline Article history: \\
Received Aug 21, 2018 \\
Revised Oct 14, 2018 \\
Accepted Oct 30, 2018 \\
\hline Keywords: \\
Curriculum \\
Curriculum design \\
Curriculum design information \\
system \\
Information systems
\end{tabular}

\begin{abstract}
Information system (IS) is important to institution of higher learning (IHL) especially in the domain of curriculum design. Without the support of IS, curriculum design in IHL is time-consuming, error-prone and much effort need to put in by curriculum designers. Although there are numerous IS developed in curriculum design domain for the past few years, there is still lack of specific IS curriculum design model found in IHL. This study aims to propose an IS model which provide guidance during curriculum design process. Model validation phase begin with development of prototype which explains the process of creating a prototype according to the proposed model. The study collected 80 responses from the survey and the study resulted that the IS model is useful and able to reduce time, error and effort during curriculum design process.
\end{abstract}

Copyright (c) 2018 Institute of Advanced Engineering and Science. All rights reserved.

Corresponding Author:

Thong Chee Ling,

UCSI University,

Kuala Lumpur, Sarawak, Terengganu, Malaysia.

Email: pavankumar.e2016@vitstudent.ac.in

\section{INTRODUCTION}

Nowadays the importance of information technology is increasing in education industry. The application of technology particularly in the area of teaching and learning at curriculum design level is growing [1]. Throughout the years, there has been quite a number of Institutions of Higher Learning (IHL) progressively involved in technological application at curriculum design level especially in developed countries such as USA, Canada, UK and Australia [2-3]. Among all IS, there are: Authoring Instructional Materials (AIM) system, which is a set of software tools for curriculum design and maintenance for use in the Navy [4]; Curriculum Information System (CIS) is being developed to provide comprehensive summaries of curricula content and structure [5]; and Curriculum Management System (CMS) which is an automated system supports entire curriculum process from planning to implementation to assessment and it also known as an automated system that supports the definition, visualization, analysis and assessment of an educational institutions desired curriculum [6]. Others are Curriculum Management and Information Tool (CurrMIT) is used in the field of medicine in IHL which is used to manage medical school curriculum and it is released and used by medical school members since 1999 [7]; Web-based application that helps in designing any curriculum in real time and allowing the verification of the proposed curriculum coherence and the generation of statistics necessary for academic and accreditation purpose [8]; and Curriculum Design System (CDS) is used to redesign information system programme [2]. Decebo is the Learning Management System (LMS) which recognised as the best tools to design and manage curricula. LMSs are neutral and able to be used to design and manage all types of curricula, not in particular field [9].

Although there are numerous IS for curriculum design in IHL, there is a lack of step-by-step guidance to curriculum designers throughout the design process. It is further confirmed through the preliminary study conducted earlier prior to this study [10]. The difficulties faced by curriculum designers during the design process includes the mapping of course learning outcome (CLO) to appropriate learning domain, aligning CLO to teaching and learning activities (TLA), aligning CLO to assessment tasks (AT) and 
meeting accreditation requirements such as student learning time (SLT). Furthermore, the preliminary study also found that without the support of IS, the design process is time-consuming, error prone and much effort are required. Although the literature concludes that there are numerous IS for curriculum design in the market, the research on IS for curriculum design that provides guidance in accomplishing the task is scarce.

\section{LITERATURE REVIEW}

There are many activities involved in curriculum design process and IS is able to play its role in managing the activities efficiently. For example, a curriculum design information system is developed to cater the needs of facilitating alignment between university and learner providers [11]. A curriculum design web-based engine which manages curriculum consistency is developed to ensure a proper balance of learning opportunities, eliminate redundancies, and assurance a coherent curriculum [8]. Curriculum designers are able to input curriculum data into database, and confirmation of data is performed to ensure it meets the accreditation requirements. Others relevant IS such as Curriculum Management and Information Tool (CurrMIT) which is used to manage medical curriculum. This tool contains basic information about almost all required courses being offered in North America. It is used to document details of instruction such as outcomes, objectives, resources, and content included in the curriculum. CurrMIT helps curriculum designers to perform their job much easier and more efficiently. They are able to do data entry via a web-based user interface and do a close scrutiny of course content and align course objectives with course content.

\subsection{The Basic Concepts of Information System}

There are two main concepts of IS and Management Information System (MIS) applied in this study: Laudon and Laudon [12] and Raymond [13]. Laudon and Laudon [12] technically define IS as a set of components which are interrelated that can collect (or retrieve), store, process and distribute information to support decision making and control in an organization. IS contains information, the data that have been shaped into a form (such as report) that is meaningful and useful to people (or employees) in an organization. There are three main activities of IS that produce information that organization needs. These activities are: input, processing and output. Input captures raw data from organization or external environment; processing converts raw data into meaning form and output transfer processed information to people or activities that use it. Feedback is the output returned to appropriate members of an organization to help evaluate or convert input stage. Environment actors such as customers, stakeholders and regulatory agencies interact with the organization and IS. The basic activities of IS are adopted and become the fundamental basis of Curriculum Design IS Model development in this study.

Raymond [13] describes IS as a computer-based information system (CBIS) in organization to provide information for problem solving. MIS is considered one of the major CBIS. Raymond [13] defines MIS as a computerized-based system that makes information available to users with similar needs. This model is originally developed for accounting information system and it contains components such as database, report writing software (or software programs) and mathematical model.

\subsubsection{The Basic Concepts of Curriculum Design}

This paper defines curriculum as a plan for action or a written document that includes strategies for achieving desired goals [14]. Curriculum design is defined as the process of defining and organizing curriculum components into a logical pattern. The work of defining and organizing curriculum components lies on the shoulder of curriculum designers. Curriculum designers are the educators who place some order or rationality in the process of designing a curriculum based on an advocating models (or curriculum model). The model is grouped into two: descriptive and prescriptive models [15]. Outcome Based Education (OBE) is grouped under prescriptive model. OBE is an education philosophy organized to several basic beliefs and principles for the learners. It starts with the belief that student could profit from any educational programme only when the outcomes are measurable as a result of any instructions [16]. OBE requires in addition to the specification of learning outcomes [17]. A close match between the outcomes and contents, the teaching methods and learning strategies (or known as TLAs) and the assessment (or known as ATs). Additionally, OBE specifies outcomes and levels of outcomes. Learning outcomes are described in terms of cognitive, affective and psychomotor domains [18]. In order to design OBE curriculum, these distinguishing features serve as reference points for designing curriculum in IHL. Constructive alignment is also one of the key features of OBE [19].

The concept of curriculum alignment is widely accepted as a main standard governing curriculum design. According to Biggs and Tang [20], 'alignment' refers to a learning environment where the key curriculum components such as TLAs and ATs are aligned to the intended learning outcome (ILO). Bloom's 
taxonomy is also being used in constructive alignment. This paper uses Bloom's Taxonomy for specification of learning outcomes at the course level.

\subsubsection{Methodology}

The research methodology consists of three main phases: (i) literature review, (ii) model development and (iii) prototype development and model validation. Firstly, the literature review provides review analysis of current and relevant literature in order to identify the important components of the IS model. Secondly, model development phase explains the creation of IS model based on phase one. The model verification which verifies components in IS model is performed in earlier study and the evaluation results have shown appropriateness and importance of the components [21-22]. Thirdly, a prototype is developed and model validation is performed through prototype development.

The process of prototype development and model validation was developed in accordance to the processes proposed by Sommerville [23]. The processes are performing an initial analysis, define prototype objective, specify prototype and construct prototype. Initial analysis is performed through the development of the proposed IS model in phase one; the objective of the prototype is to validate the proposed IS model through the evaluation of the prototype; each function of the prototype which is relevant to curriculum design are discussed in the following section; and the prototype is built using J2EE technology. It consists of the principal components: glassfish 3 webserver, firebird database, Java, JavaScript and HTML.

\section{RESULTS AND DISCUSSION} discussions

This section is divided into three parts: the proposed model, prototype development, and results and

\subsection{The Proposed Model}

The proposed model integrating the concepts of IS with curriculum design. Figure 1 presents the general overview of the proposed model. Curriculum Design Module is the main component of managing and monitoring curriculum design process. Its subcomponents are: Curriculum Maintenance, Curriculum Assessment and Curriculum Analysis. Curriculum Maintenance is the main mechanism of data entry and maintenance of Curriculum Database. Curriculum Assessment has the ability to map curriculum data such as course learning outcome (CLO) to OBE Learning Outcomes (LO) Domains such as Malaysian Qualification Agency (MQA) LO Domain and align teaching and learning activities (TLAs) and assessment tasks (ATs) with CLO.

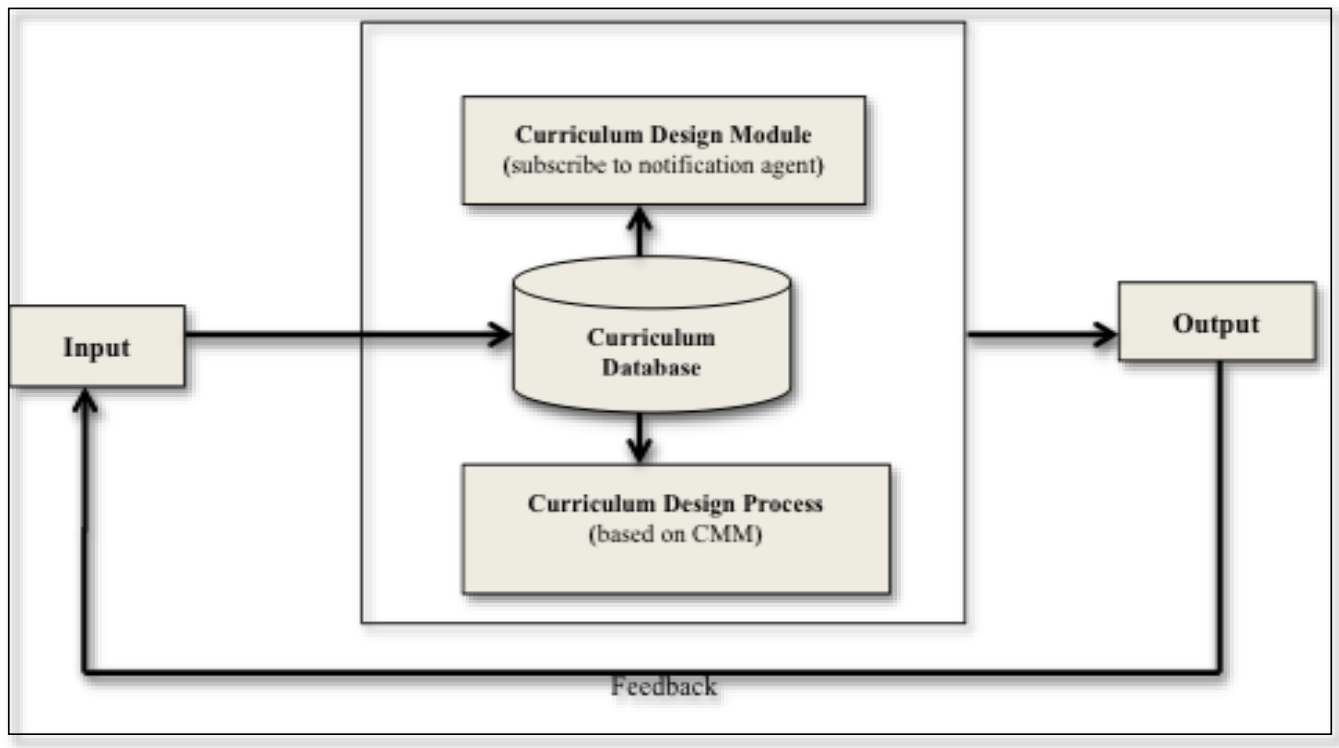

Figure 1. Information System Curriculum Design Model

Curriculum Design Process demonstrates the degree to which each curriculum design process has achieved the expected requirements. It donates to the software agent, which is able to capture the possible 
design error based on the rules in the Curriculum Database. The Curriculum Database is a collection of design rules that have only one set of conditions, but without action statements. The internal and external data input by curriculum designers which are relevant to the design process are stored in Curriculum Database. The notification agents are capable of detecting error and providing notification and suggestions to curriculum designers. Those capabilities assist and guide the curriculum designers during the design process.

\subsubsection{The Prototype Development}

A prototype is developed based on the model after each component of the proposed model is verified [21-22]. The system architecture of the prototype is based on three-tier architecture. Figure 2 illustrates the three-tier architecture of the system.

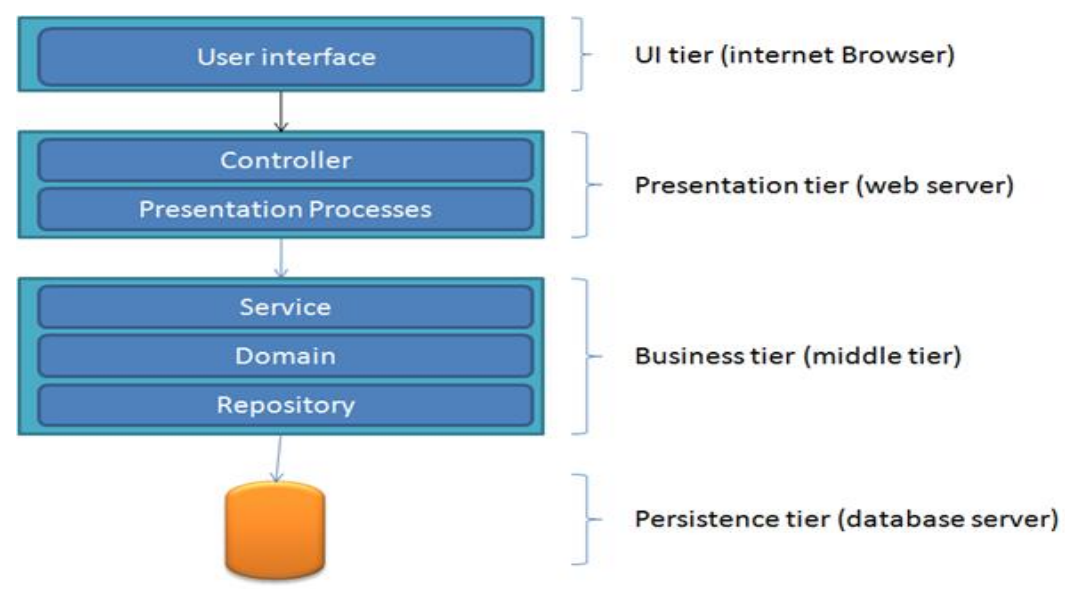

Figure 2. System Architecture

Figure 3 and Figure 4 shown the client application or presentation layer where the graphical user interface (GUI) is implemented. After logging in to the system, users are able to add and edit course information as shown in Figure 3. CLO, TLA, AT and SLT are mapped to Programme Learning Outcome (PLO) at programme level as shown in Figure 4.

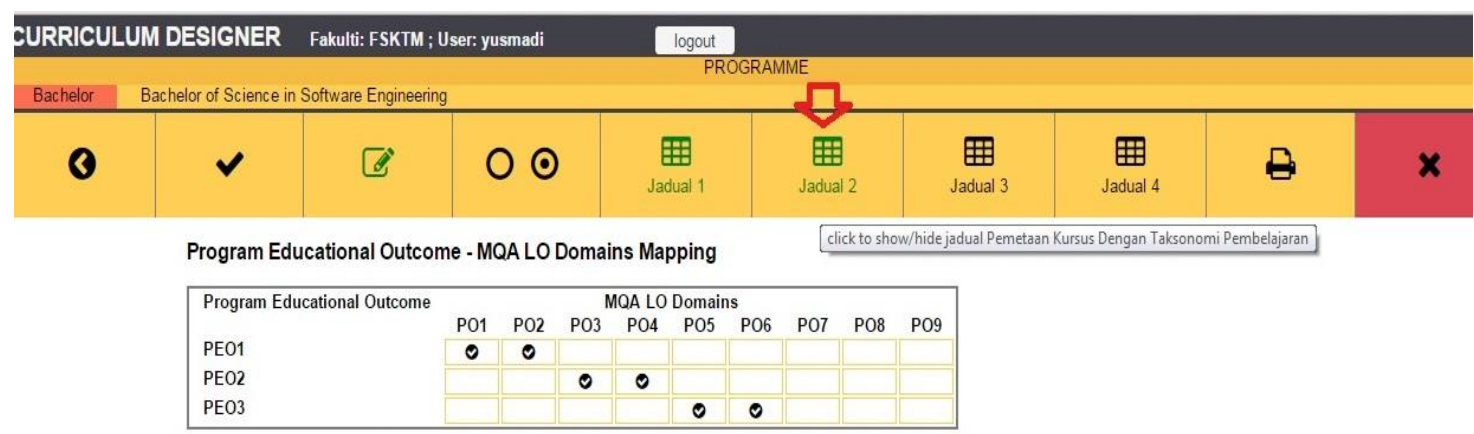

Jadual Pemetaan Hasil Pembelajaran Kursus Dengan Hasil Pembelajaran

\begin{tabular}{|c|c|c|c|c|c|c|c|c|c|c|c|c|}
\hline \multirow[t]{2}{*}{ bil } & \multirow[t]{2}{*}{ Kod kursus } & \multirow[t]{2}{*}{ Nama kursus } & \multirow[t]{2}{*}{ Kredit } & \multicolumn{9}{|c|}{ HASIL PEMBELAJARAN PROGRAM } \\
\hline & & & & P01 & $\mathrm{PO2}$ & $\mathrm{PO} 3$ & P04 & P05 & PO6 & $\mathrm{P} 07$ & P08 & P09 \\
\hline \multicolumn{13}{|c|}{ KURSUS UNIVERSITI } \\
\hline 1 & KOM 3403 & Pengucapan Awam & 3 & & & & 0 & & 0 & & & 0 \\
\hline 2 & MGM 3180 & Asas Keusahawanan & 3 & & & & 0 & & 0 & & 0 & \\
\hline 3 & SKP 2101 & Kenegaraan Malaysia & 3 & 0 & & & & 0 & 0 & & & \\
\hline 4 & SKP 2203 & Tamadun Islam dan Asia & 2 & 0 & & & & 0 & & 0 & & \\
\hline 5 & SKP 2204 & Hubungan Etnik & 2 & 0 & & & & 0 & 0 & & & \\
\hline 6 & PRT 2008 & Pertanian dan Manusia & 2 & 0 & & & & 0 & 0 & & & \\
\hline 7 & BBI 2420 & Oral Interaction Skills & 3 & & & & 0 & & 0 & 0 & & \\
\hline 8 & BBI 2421 & General Writing Skills & 3 & & & 0 & & & 0 & 0 & & \\
\hline
\end{tabular}

Figure 3. Course Design 


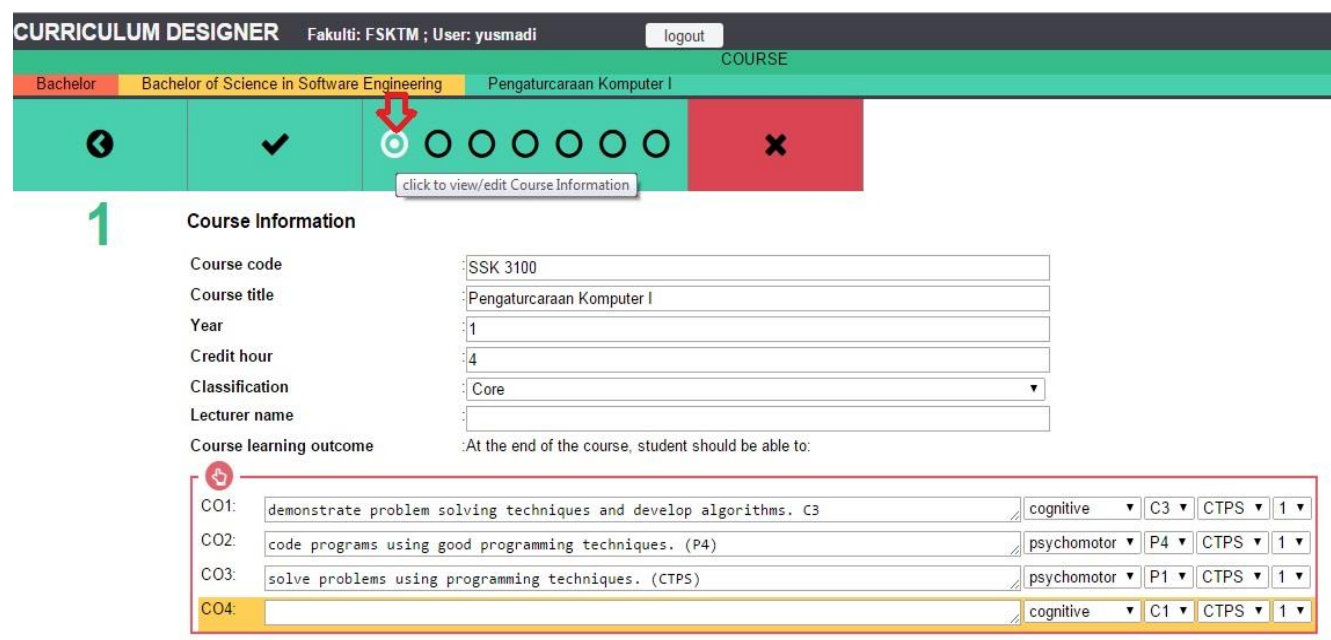

Figure 4. Course Mapping

\subsection{Model Validation}

Technology acceptance test is conducted through an online survey to obtain the acceptability of the prototype. The test is conducted based on Technology Acceptance Model (TAM) introduced by Davis [24]. TAM is selected in this research because it is one of the models that analyzes user behavior to accept and use a new technology. Furthermore, TAM has been implemented in many field of studies and is growing popular as it is simple and easy to understand [25].

The research question for model validation is: What are the usability and acceptance of the proposed model. Snowball sampling technique was applied to test the prototype and an online survey is conducted to gauge the usability of the prototype. The questionnaire (refer to appendix) is specifically designed to include three aspects of perceived usefulness, one aspect of ease-of-use, two aspects of attitude and two aspects of intention to use.

There are five hypotheses adapted from Davis [24] based on TAM in this paper. The simple and multiple regression analysis are used for hypothesis testing. SPSS is the analytical tool use to perform the analysis. Four hypotheses (H1 to H4) are accepted and one hypothesis (H5) is rejected. When significant value $(\mathrm{p}=0.000)$ is less than 0.05 , it indicates that at least one independent variables such as perceived ease of use (PEU) has a significant relationship with the dependent variable such as usefulness (PU). If the unstandardized coefficient is a positive value such as 0.568 , and p-value is 0.000 , it can be interpreted as there is a significant positive relationship between PEU and PU. The summary results of hypothesis testing are presented in appendix.

In conclusion, attitude towards using the system does not have a significant effect on intention to use the system. Basically, the respondents conclude that perceived usefulness and ease of use of using the system have positive impact on attitude of using the system. The findings also show that perceived usefulness has direct or positive impact on intention to use. Usefulness has made curriculum designers intend to use the system. This has been supported by Davis [24] and Masrom [26] the prior research shows determining that attitude has no effect on intention to use. This means that intention to use and attitude to use the system are of two different constructs. It is proved that the curriculum designers in IHL accepted the system as it is shown that the mean value scored more than 3.0.

\section{CONCLUSION}

In this study, a model is proposed for curriculum designers and this model is validated through prototype evaluation. The two processes are conducted in order to address issues raised by the curriculum designers during the study conducted earlier. The prototype is evaluated in order to determine its usefulness, ease of use, attitude towards and intention to use the system. The findings indicate that the prototype is an easy, effective and useful system to help curriculum designers in designing curriculum. This brings about the positive frame of mind towards using the system. This leads to the conclusion that proposed model can be used by curriculum designers in performing their work in a systematic manner with step-by-step guide during the design process. 


\section{REFERENCES}

[1] Smith, R and Killen, C. 2013. "Using Technology to Improve Curriculum Design," Report of Enhancing Curriculum Design with Technology from JISC.

[2] Slack, J. M., 2011. "A Curriculum Design System for Information System Programs," in Proceedings of Information Systems Education Conference (ISECON), Wilmington North Carolina, USA. V.28. N649.

[3] Walker, J., 2013. "Enhancing Curriculum Design with Technology,". Retrieved September 5, 2017 from http://www.rscscotland.org/newsfeed/2013/09/03/enhancing-curriculum-design-with-technology-new-jiscpublication/

[4] Wallace H. W. II, Janet, L.D., James A. and Jerry, L. V. 1993. "The Automation of Curriculum Development Using the Authoring Instructional Materials (AIM) System.” Instructional Science, 21(4), 255-267.

[5] Friedman, C. P., \& Nowacek, G. 1995. "Issues and Challenges in the Design of Curriculum Information Systems," Academic Medicine, 70(12), 1096-1105.

[6] Wilkes, F. A., Johnson, D. W., \& Ormond, P. 2002. "Is a Curriculum Management System in Your Future?” In Inf. Syst. Educ. Conf., San Antonio, TX.

[7] Joshua, J., Salas, A., Cameron, T., Naguwa, G., \& Kasuya, R. 2005. "Implementing an Online Curriculum Management Database in a Problem-based Learning Curriculum," Academic Medicine, 80(9).

[8] Hamam, H. and Loucif, S. 2009. "Web-based Engine for Curriculum Designer," Education IEEE Transactions, 52(4), pp. 563-572.

[9] Piccioli V. 2014. "Curriculum Design and Curriculum Lifecycle," Retrieved Feb 12, 2018 from https://www.docebo.com/2014/08/11/curriculum-design-lifecycle/

[10] Thong C.L., Yusmadi Y.J., Rusli A., Nor H.A. and Lee K.C. 2011. "Identifying Difficulties in Curriculum Design for Institution of Higher Learning in Malaysia," in Abstract of The Academic Development in Higher Education, Selangor.

[11] Dafoulas, G., Barn, B., and Zheng, Y. 2012. "Curriculum Design Tools: Using Information Modeling for Course Transformation and Mapping," In Information Technology Based Higher Education and Training (ITHET) International Conference, pp. 1-5.

[12] Laudon, K.C. and Laudon, J.P. 2014. "Management Information Systems: Managing the Digital Firm," Twelfth Edition, Pearson, pp. 17.

[13] Raymond M.J. 1998. Management Information Systems, 6th Ed. New Jersey: Prentice Hall.

[14] Orntein, A.C., and Hunkin, F.P. 2009. "Curriculum Foundations, Principles and Issues," Fifth edition. Pearson.

[15] Prideaux, D. 2003. "ABC of Learning and Teaching in Medicine: Curriculum Design," BMJ: British Medical Journal (326:7383), pp. 268.

[16] Ghazali, M.M., Saundi, T., Mustapha, K.M., Konting A.N., Man, A. A, and Norizah, S. A. 2008. "Implementation of Outcome-based Education in Universiti Putra Malaysia: A Focus on Students' Learning Outcomes," International Education Studies, Vol. 1, No. 4, pp. 147-160.

[17] Harden, R.M. 2007. "Outcome-based Education-the Ostrich, the Peacock and the Beaver," Medical Teacher, 29(7), pp. 666-671.

[18] Bloom, B.S., Engelhart, M.D., Furst, E.J., Hill, W. H., Krathwohl, D.R. 1956. "Taxonomy of Educational Objectives: Handbook I: Cognitive Domain," New York: David McKay.

[19] Biggs, J.B. and Tang, C. 2011. "Teaching for Quality Learning at University," McGraw-Hill International.

[20] Biggs, J.B., and Tang, C. 2008. "Constructive Alignment in Learning, Teaching and Assessment," ATN Assessment Conference Engaging Students in Assessment, U of SA.

[21] Thong C.L., Yusmadi Y. J., Rusli A., and Nor H.A. 2016. "Expert Review on Capability Maturity Model in Curriculum Design," in Proceedings of Teaching and Learning Conference (ICTLS), Kuala Lumpur, Malaysia, pp. 379-382.

[22] Thong C. L., Yusmadi Y. J., Rusli A., and Nor H.A. 2017. "Users' Verification of Curriculum Design Information Model," in Lecture Notes in Data Engineering and Communication Technologies (LNDECT), Springerlink Book Series, pp. 824-831.

[23] Sommerville, I. 2010. Software engineering (9th ed.). Essex Pearson Education Limited.

[24] Davis, F.D. 1989. "Perceived Usefulness, Perceived Ease of Use, and User Acceptance of Information Technology," MIS Quaterly (13:3), pp. 319-340. Focus on Students' Learning Outcomes 2008. International Education Studies, Vol. 1, No.4, pp. 147-160.

[25] King, W.R. and He. J. 2006. “A Meta-analysis of the Technology Acceptance Model," Journal of Information and Management, 43(6), pp.740-755.

[26] Masrom, M. 2007. "Technology Acceptance Model and E-Learning," in Proceeding on 12th International Conference Education, Sultan Hassanal Bolkiah, Institute of Education, Universiti Brunei Darussalam, pp. 1-10. 


\section{APPENDIX}

Summary Results of Hypothesis Testing

\begin{tabular}{|l|c|c|c|}
\hline \multicolumn{1}{|c|}{ Hypotheses } & $\begin{array}{c}\text { Unstandardized } \\
\text { Beta }\end{array}$ & $\begin{array}{c}\text { p-value } \\
(<\mathbf{0 . 0 5}=\mathbf{s i g})\end{array}$ & Outcome \\
\hline $\begin{array}{l}\text { H1: Perceived ease of use has a significant positive effect } \\
\text { on the perceived usefulness of the system }\end{array}$ & 0.568 & 0.000 & Accepted \\
\hline $\begin{array}{l}\text { H2: Perceived ease-of-use has a significant positive effect } \\
\text { on attitude towards the system }\end{array}$ & 0.109 & 0.015 & Accepted \\
\hline $\begin{array}{l}\text { H3: Perceived usefulness has a significant positive effect } \\
\text { on attitude towards the using of the system }\end{array}$ & 0.098 & 0.011 & Accepted \\
\hline $\begin{array}{l}\text { H4: Perceived usefulness has a significant effect on } \\
\text { intention to use }\end{array}$ & 0.165 & 0.003 & Accepted \\
\hline $\begin{array}{l}\text { H5: Attitude towards using of the system has a significant } \\
\text { effect on intention to use }\end{array}$ & 0.091 & 0.556 & Rejected \\
\hline
\end{tabular}

Questionnaire for Technology Acceptance Test

\section{Part A: Perceived Usefulness}

Please cross (X) where appropriate: 1. Strongly Disagree, 2. Disagree, 3. Neutral, 4. Agree, 5. Strongly Agree.

\begin{tabular}{|c|c|c|c|c|c|c|}
\hline & & 1 & 2 & 3 & 4 & 5 \\
\hline 1 & It saves my time when I use it in completing my task & & & & & \\
\hline 2 & It makes the things I want to accomplish easier to get done & & & & & \\
\hline 3 & It helps me to perform my work faster with less error & & & & & \\
\hline 4 & It does things I would expect it to do & & & & & \\
\hline 5 & It meets my needs & & & & & \\
\hline 6 & $\begin{array}{l}\text { It helps me in complying with requirements of MQA } \\
\text { (e.g. Student Learning Time) }\end{array}$ & & & & & \\
\hline 7 & It validates input save me a lot of time by identifying error & & & & & \\
\hline 8 & It generate useful report & & & & & \\
\hline
\end{tabular}

\section{Part B: Perceived Ease of Use}

Please cross (X) where appropriate: 1. Strongly Disagree, 2. Disagree, 3. Neutral, 4. Agree, 5. Strongly Agree.

\begin{tabular}{|c|c|c|c|c|c|c|}
\hline & & 1 & 2 & 3 & 4 & 5 \\
\hline 9 & It is simple to use as compared to paper-based system & & & & & \\
\hline 10 & It is easy to use to complete my task & & & & & \\
\hline 11 & It guides me throughout the design process & & & & & \\
\hline 12 & It saves my effort when I use it in completing my task & & & & & \\
\hline 13 & It requires fewer steps to accomplish my work & & & & & \\
\hline 14 & Users would like to use it & & & & & \\
\hline 15 & I can recover from mistakes quickly and easily & & & & & \\
\hline 16 & I can use it successfully every time & & & & & \\
\hline
\end{tabular}

\section{Part C: Attitude}

Please cross (X) where appropriate: 1. Strongly Disagree, 2. Disagree, 3. Neutral, 4. Agree, 5. Strongly Agree.

\begin{tabular}{|l|l|l|l|l|l|l|}
\hline & $\begin{array}{l}\text { It is a good idea to use C2DIS in performing my task as } \\
\text { compared to paper-based system }\end{array}$ & 1 & 2 & 3 & 4 & 5 \\
\hline 18 & My attitude towards using C'DIS is very favorable & & & & & \\
\hline
\end{tabular}

\section{Part D: Intention to Use}

Please cross (X) where appropriate: 1. Strongly Disagree, 2. Disagree, 3. Neutral, 4. Agree, 5. Strongly Agree.

\begin{tabular}{|l|l|l|l|l|l|l|}
\hline \multicolumn{2}{|c|}{} & 1 & 2 & 3 & 4 & 5 \\
\hline${ }^{20}$ & I intend to use C2DIS when it is available & & & & & \\
\hline & $\begin{array}{l}\text { I think curriculum designers should use C2DIS in } \\
\text { performing their task }\end{array}$ & & & & \\
\hline
\end{tabular}

